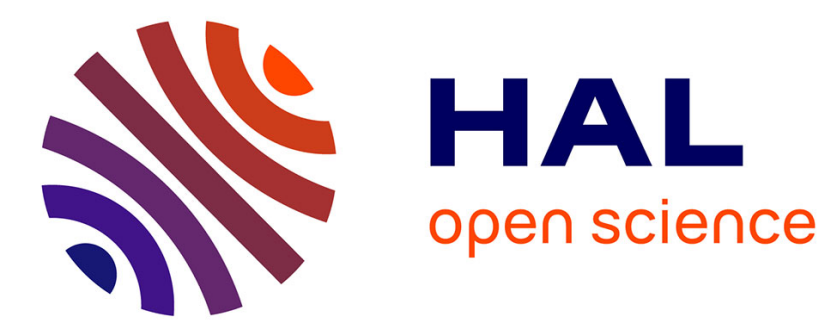

\title{
Fine structure of the (A0 X) complex in InP
}

\author{
H. Mathieu, J. Camassel, F. Ben Chekroun
}

\section{To cite this version:}

H. Mathieu, J. Camassel, F. Ben Chekroun. Fine structure of the (A0 X) complex in InP. Revue de Physique Appliquée, 1983, 18 (12), pp.741-743. 10.1051/rphysap:019830018012074100 . jpa00245140

\section{HAL Id: jpa-00245140 https://hal.science/jpa-00245140}

Submitted on 1 Jan 1983

HAL is a multi-disciplinary open access archive for the deposit and dissemination of scientific research documents, whether they are published or not. The documents may come from teaching and research institutions in France or abroad, or from public or private research centers.
L'archive ouverte pluridisciplinaire HAL, est destinée au dépôt et à la diffusion de documents scientifiques de niveau recherche, publiés ou non, émanant des établissements d'enseignement et de recherche français ou étrangers, des laboratoires publics ou privés. 
Classification

Physics Abstracts

$71.35-71.55 \mathrm{~F}-71.70 \mathrm{E}$

\title{
Fine structure of the $\left(A^{0} X\right)$ complex in InP
}

\author{
H. Mathieu, J. Camassel and F. Ben Chekroun \\ Groupe d'Etude des Semiconducteurs $\left({ }^{*}\right)$, Université des Sciences et Techniques du Languedoc, \\ 34060 Montpellier Cedex, France
}

(Reçu le 25 juillet 1983, accepté le 29 août 1983)

\begin{abstract}
Résumé. - Nous présentons des mesures de photoluminescence sous contrainte uniaxiale associées à l'exciton lié à un accepteur neutre dans InP. Les résultats sont analysés suivant deux schémas théoriques : le schéma de couplage $j-j$ et le schéma du champ cristallin. Nous montrons que la structure fine du complexe $\left(\mathrm{A}^{0} \mathrm{X}\right)$ résulte du couplage des deux trous dans le champ cristallin cubique. Les trois états qui en résultent sont respectivement $\Gamma_{8}$, $\Gamma_{7,8}, \Gamma_{6}$ dans l'ordre des énergies croissantes, l'énergie d'échange électron-trou étant négligeable.
\end{abstract}

\begin{abstract}
We present stress-dependent photoluminescence measurements on exciton bound to neutral acceptor in InP. We analyse the experimental results in two theoretical schemes : the $j$-j coupling scheme and the crystal field scheme. We find that the triplet structure of the $\left(\mathrm{A}^{0} \mathrm{X}\right)$ complex results from hole-hole coupling in the cubic crystal field. We show that the three bound-exciton states correspond to $\Gamma_{8}, \Gamma_{7,8}, \Gamma_{6}$ in order of increasing energies, the electron-hole exchange energy being found to be vanishingly small.
\end{abstract}

The multiplet structure of excitons bound to shallow neutral acceptor $\left(\mathrm{A}^{0} \mathrm{X}\right)$ clearly exhibits three recombination lines which have been investigated quite extensively in many semiconductors with diamond or zinc-blende structures [1-11]. Basically the bound exciton states are made of an electron and two holes localized into the Coulomb field of the acceptor. The two identical holes with $j=3 / 2$ couple to form a singlet $j=0$ and a quintet $j=2$. In order to account for the triplet structure of the radiative recombination spectrum (see Fig. 1), another interaction must be taken into consideration which gives rise to a splitting of the $j=2$ two-hole state. This interaction may be either the electron-hole exchange or the cubic crystal field. No effect associated with a mixing of these two interactions with comparable magnitude can be seriously taken into consideration since, in this case, four recombination lines would be resolved. This is opposite to the experimental finding.

In the $j-j$ coupling scheme (jjcs), the further interaction of the two-hole states with the electron yields $j=1 / 2,3 / 2,5 / 2$. The crystal field splitting of the $j=5 / 2$ quintet is assumed in this case to be vanishingly

(*) Laboratoire associé au CNRS.

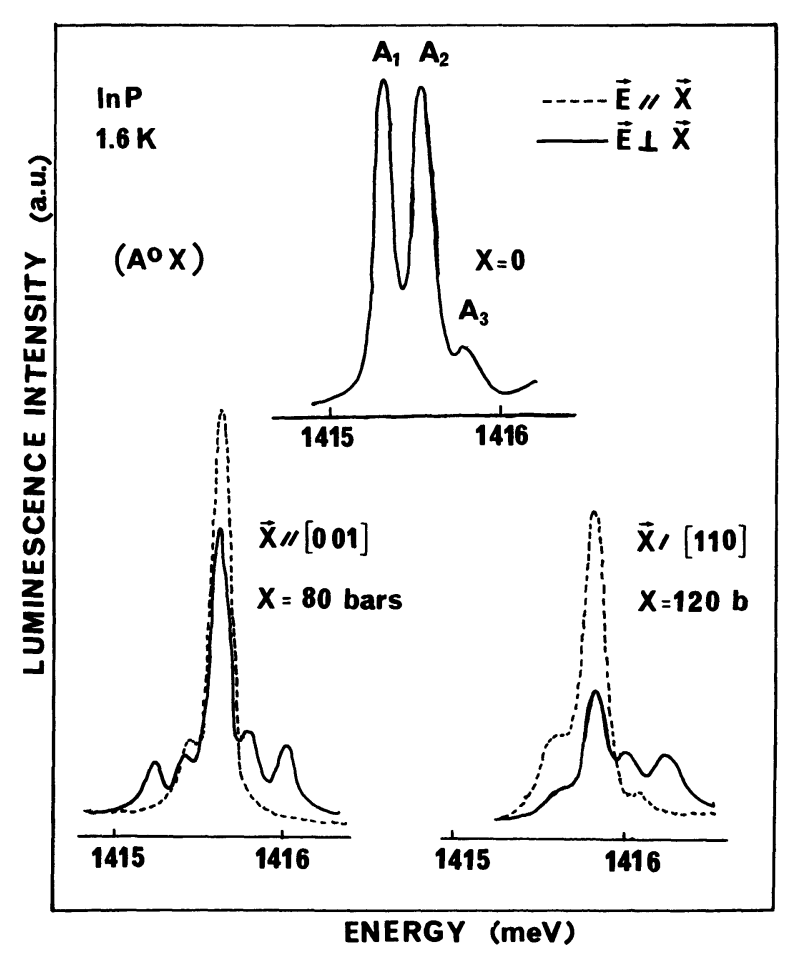

Fig. 1. - Typical photoluminescence spectra obtained at $1.6 \mathrm{~K}$ under $(001)$ and (110) stress. 
small. Accordingly to this scheme, White et al. [2] assign the three $\left(\mathrm{A}^{0} \mathrm{X}\right)$ luminescence lines in InP to the recombination of the $j=5 / 2,3 / 2,1 / 2$ states in order of increasing energies. In the closely related compound GaAs, Schmidt et al. [10] proposed also the (jjcs). In the crystal field scheme (cfs), the ordering of the level is quite different. The $j=0$ and $j=2$ two-hole states give rise to $\Gamma_{1}(j=0)$ and $\Gamma_{3}+\Gamma_{5}$ $(j=2)$. A further coupling with the electron gives $\Gamma_{6}\left(\Gamma_{1}\right), \Gamma_{8}\left(\Gamma_{3}\right)$ and $\Gamma_{7,8}\left(\Gamma_{5}\right)$. The splitting $\Gamma_{7}-\Gamma_{8}$ associated to the electron-hole exchange interaction is assumed to be vanishingly small. In this way, both Elliott et al. [4] and Weber et al. [11] concluded that the series of $\left(\mathrm{A}^{0} \mathrm{X}\right)$ lines associated to $\mathrm{Al}, \mathrm{Ga}$ and $\mathrm{In}$ in silicon corresponds to the radiative recombinations of the $\Gamma_{6}, \Gamma_{7,8}$ and $\Gamma_{8}(\mathrm{cfs})$ states in order of increasing energies.

In this work, we investigate the stress-induced splitting of the $\left(\mathrm{A}^{0} \mathrm{X}\right)$ states in InP. We used highresolution luminescent experiments, performed at $1.6 \mathrm{~K}$, on high-quality VPE samples. The luminescence lines result from transitions between the $\left(\mathrm{A}^{0} \mathrm{X}\right)$ initial states and the $\left(\mathrm{A}^{0}\right)$ final state $\left(1 \mathrm{~s}^{3 / 2}\right.$ acceptor ground state). Now, when a uniaxial stress is applied to the crystal, according to the stress-splitting of the top most valence band, both the $\left(\mathrm{A}^{0} \mathrm{X}\right)$ and the $\left(\mathrm{A}^{0}\right)$ states split into sublevels. The $1 \mathrm{~s}^{3 / 2}$ acceptor state gives rise to two sublevels whatever the stress direction is. On the other hand the $\left(\mathrm{A}^{0} \mathrm{X}\right)$ states gives rise to a series of sublevels which depend upon the coupling scheme. i) in the (jjcs), the $j=1 / 2,3 / 2,5 / 2$ states are spherical ones so that, taking the stress-direction as the quantization axis, $m_{j}$ remain a good quantum number and the stress splitting of the $\left(\mathrm{A}^{0} \mathrm{X}\right)$ state is qualitatively equivalent whatever the stress-direction may be. ii) on the contrary in the (cfs) the $\Gamma_{6}\left(\Gamma_{1}\right), \Gamma_{8}\left(\Gamma_{3}\right)$ and $\Gamma_{7,8}\left(\Gamma_{5}\right)$ states are cubic ones, so that their stressbehaviour are function of the stress-direction. In particular a $(001)((111))$ stress splits the $\Gamma_{3}\left(\Gamma_{5}\right)$ state but does not the $\Gamma_{5}\left(\Gamma_{3}\right)$ state, however a (110) stress split both the $\Gamma_{3}$ and $\Gamma_{5}$ states. As a consequence if the basis states of the complex are spherical, as required in the (jjcs), the stress behaviour of the luminescence spectrum must be independent of the stress-direction, to the first order. On the opposite if they are cubic states, as required in the (cfs), the stress-behaviour must depend on the stress-direction.

We have investigated the stress-behaviour of the luminescence spectrum under both (001) and (110) stress-direction. Typical spectra are given in figure 1. At zero stress, the fine structure resolved presents two strong lines separated by $0.23 \mathrm{meV}$ and a third one, very weak, situated about $0.25 \mathrm{meV}$ above the higher energy strong line. For the (001) and (110) stressdirection, clearly we observe the stress-splitting of the transition lines. The stress dependence of the structures are given in figure 2 and figure 3. Clearly the stress-behaviours are not qualitatively equivalents. The $\mathrm{A}_{3}$ component gives rise to two subcomponents what-

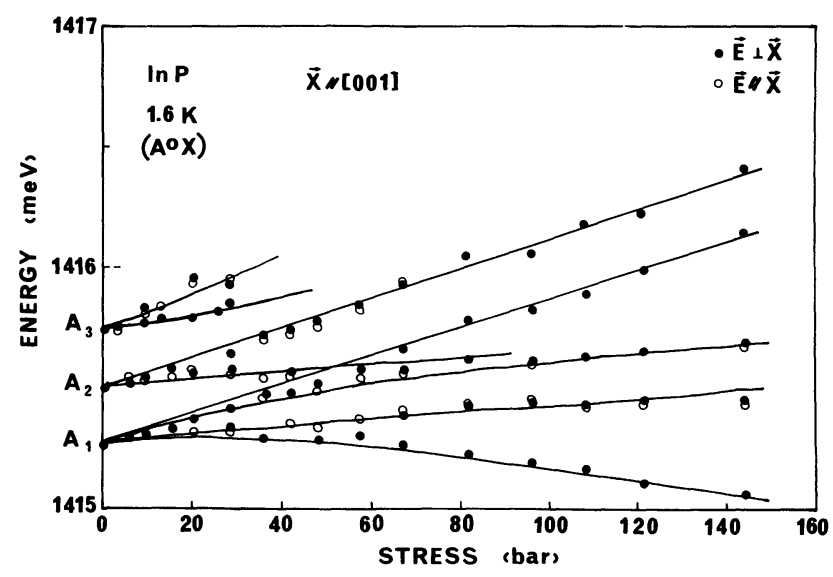

Fig. 2. - Stress dependence of the transition lines, under (001) stress. Solid circles and open circles correspond to $\sigma$ and $\pi$ polarization respectively.

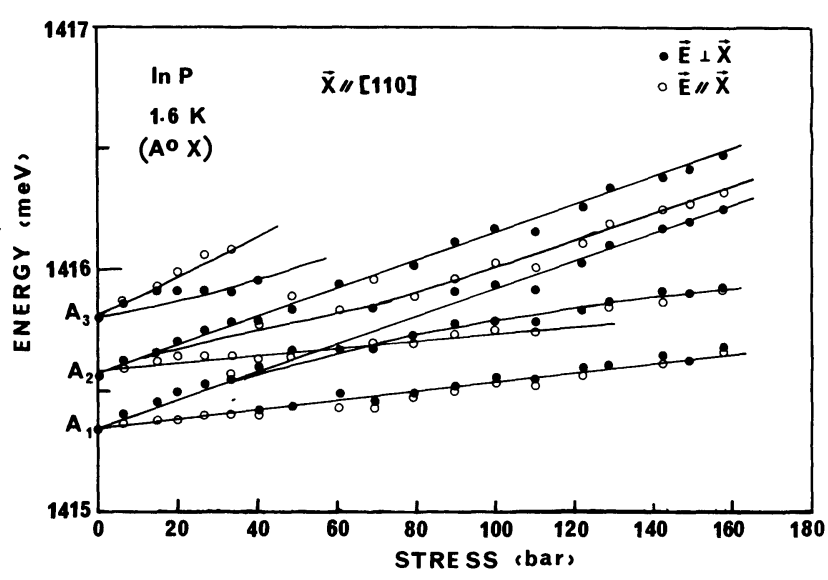

Fig. 3. - Stress dependence of the transition lines, under (110) stress.

ever the stress-direction is : this results from the stresssplitting of the $\left(\mathrm{A}^{0}\right)$ final state only the corresponding $\left(A^{0} X\right)$ initial state does not split. The $A_{2}$ component clearly splits into two subcomponents for (001) stress and at least three subcomponents for (110) stress. As a result, the corresponding $\left(\mathrm{A}^{0} \mathrm{X}\right)$ initial state splits under (110) stress but does not under (001). Clearly this agrees with the (cfs) but not with the (jjcs). Lastly the $A_{1}$ component clearly exhibits four subcomponents under (001) stress and at least three subcomponents under (110) stress : as a result the corresponding $\left(\mathrm{A}^{0} \mathrm{X}\right)$ initial state splits in both stress-configurations. Now considering the (cfs), the $\Gamma_{6}$ state does not split, the $\Gamma_{7-8}$ state splits under (110) stress only and the $\Gamma_{8}$ state splits under both (001) and (110) stress, so we attribute the $\mathrm{A}_{1}, \mathrm{~A}_{2}, \mathrm{~A}_{3}$ structures to the $\Gamma_{8}, \Gamma_{7-8}, \Gamma_{6}$ $\left(\mathrm{A}^{0} \mathrm{X}\right)$ states respectively. 
As a conclusion we believe that the fine structure of the $\left(\mathrm{A}^{0} \mathrm{X}\right)$ levels results probably from the crystal field-scheme. First the two holes couple to give $j=0$ and $j=2$, the $j=2$ two hole state then splits in the cubic crystal field into $\Gamma_{3}$ and $\Gamma_{5}$. Taking account of the electron, without any electron-hole exchange interaction, the resulting bound exciton states are $\Gamma_{8}$, $\Gamma_{7-8}$ and $\Gamma_{6}$ in order of increasing energies.

\section{References}

[1] Skolnick, M. S. and Dean, P. J., Proceedings of the 16th International Conference on the Physics of Semiconductors, Montpellier 1982 (North-Holland, ed. Averous), p. 266.

[2] White, A. M., Dean, P. J. and Day, B., J. Phys. C 7 (1974) 1400 .

[3] Thewalt, M. L. W., Phys. Rev. Lett. 38 (1977) 521.

[4] Elliott, K. R., Orbourn, G. C., Smith, D. L. and MCGill, T. C., Phys. Rev. B 17 (1978) 1808.

[5] Bimberg, D., Schairer, W., Sondergeld, M., YeP, T. O., J. Lumin. 3 (1970) 175.

[6] White, A. M., Minchliffe, I., Dean, P. J. and Greene, P. D., Solid State Commun. 10 (1972) 497.
[7] Schairer, W., Bimberg, D., Kohler, W., Cho, K. and Schmidt, M., Phys. Rev. B 13 (1976) 3452.

[8] Rhuehle, W. and Bimberg, D., Phys. Rev. B 12 (1975) 2382.

[9] Dean, P. J., Faulkner, R. A., Kimura, S. and IleGEMS, M., Phyś. Rev. B 4 (1971) 1926.

[10] Schmidt, M., Morgan, T. N., Schairer, W., Phys. Rev. B 11 (1975) 5002.

[11] Weber, J., Conzelmann, M. and Sauer, R., Proceedings of the 15th int. conf. on the Physics of semiconductors, Kyoto 1980, J. Phys. Soc. Japan 49 (Suppl. A) (1980) 425. 